\title{
CREATING A SOFTWARE SYSTEM WITH FUNCTIONALITY TO HELP MAKE IT ACCESSIBLE FOR PEOPLE WITH A VISUAL DEFICIT Negoslav Sabev ${ }^{1}$, Galya Georgieva-Tsaneva ${ }^{2}$, Galina Bogdanova ${ }^{3}$
}

\begin{abstract}
The software systems that millions of users use everyday around the world are mainly targeted at the main and the largest average group of people - people without disabilities. However, software systems are often inaccessible and unusable for another group of people - people with congenital or acquired disabilities. For a system to be accessible to people with special needs, it must be designed to take account of and be geared to their specific needs, opportunities for using the software systems and the hardware that provides them. This paper presents a model for creating a software system (for a physiological data analysis) that takes into account the needs of people with disabilities and in particular people with visual deficits. This model will ensure the assibilites of the software system and its easy use by both this target group and people without disabilities.
\end{abstract}

UDC Classification: 004.4, 304; DOI: http://dx.doi.org/10.12955/cbup.v6.1241

Keywords: software systems, people with disabilities, accessibility

\section{Introduction}

In the process of creating software systems, as well as all intelligent systems developed by people, certain approaches and methods are followed, and preliminary models are created. It is common knowledge that software systems that are being used today, both on the Internet and on separate standalone hardware devices, do not offer appropriate accessibility for disabled people. It is necessary to orientate the process of creating the software system to people with disabilities so that application developers can create the appropriate software for those users with special needs. Developers of software applications are typically people without disabilities, and they are hardly able to understand what, in particular, are the requirements that must be applied to software systems so that they can be used by people with disabilities. Therefore, it is important, during the design process, to ask for and take into account the views of people with disabilities on how a system should look and function, which they can easily and conveniently use.

The purpose of this paper is to present some methods for creating a software system that has functionality for use by people with disabilities and in particular people with visual deficits. This material can also be useful in the training of people with disabilities when using software systems (Tramonti et al., 2017).

\section{Literature review}

The principle of universality implies that computer information systems are oriented to a wide range of users regardless of their age, gender or disability (Georgieva-Tsaneva, 2017). In his study, Oviatt (2001) proposes the use of flexible interfaces as an important characteristic for universal access, given the realization of systems providing adequate access for the elderly people. According to Marilyn $\mathrm{M}$. et al. (2007), the increasing percentage of elderly people and people with different disabilities around the world raise the issue of caring for these groups of people. People with special needs, who for many years stay out of the reach of developers, are beginning to declare their desire to be able to access the web in a suitable way. In recent years, the focus has been on software systems and public Web sites, which should be able to be accessed by people with disabilities. Accessibility implies that software systems take into account the specificities of people with disabilities.

The authors Ferre et al. (2001) used the term "usability" to describe the activities in determining the system availability, performed with an appropriate user group. The definition of system accessibility is given in the standard ISO 9241, Part 11 (1998): "the extent to which a product can be used by specified users to achieve specified goals with effectiveness, efficiency, and satisfaction in a specified context of use."

\footnotetext{
${ }^{1}$ Institute of Mathematics and Informatics, Bulgarian Academy of Sciences, Sofia, Bulgaria, negoslavsabev@gmail.com

${ }^{2}$ Institute of Robotics, Bulgarian Academy of Sciences, Sofia, Bulgaria, galicaneva@abv.bg

${ }^{3}$ Institute of Mathematics and Informatics, Bulgarian Academy of Sciences, Sofia, Bulgaria, g.bogdanova@gmail.com
} 
The most complete definition of this as an accessible software or website is given in the Sherman study (2001): "A software, website or other electronic information source is accessible if someone with a disability is able to use the source's data, information, or services as effectively as someone without a disability."

Petrie (2009) offers accessibility and usability concepts that can help developers solve the issues of ensuring that software systems are used by users with disabilities and that they can improve the efficiency of the project life cycle.

It is important that accessibility issues are put in the very beginning of the work on software systems. According to Balan et al. (2010) is very expensive to provide a certain level of usability after system deployment. Landauer's (1995) research confirms that a significant part of the cost of maintaining software systems is spent on addressing usability issues.

The development of an abstract user interface (user interfaces that are tailored to the needs of specific users) has been studied in the work of Atanasova et al. (2017).

Prior activity of the authors on accessibility issues

The authors of this material have previous experience in working on providing web accessibility (Bogdanova et al., 2016; Georgieva-Tsaneva, 2017). In 2016, with the participation of authors, a "Web Accessibility Handbook" (Bogdanova et al., 2016) was created for the Horizonte Foundation's Project: "Citizenship Initiative for Web Accessibility in the Public Sector" (with the main target group being people with visual difficulties). During the implementation of the project, 30 trained volunteers (in order to obtain an objective assessment) were tested on 100 public sites for their accessibility. The authors have worked on projects for the creation of a digital center and software systems related to the digitization of the cultural and historical heritage of Bulgaria and have experience in addressing issues of accessibility of people with visual deficits to systems that store information (Georgieva-Tsaneva et al., 2017); as well as on information protection issues (Bogdanova G. et al., 2017).

The present material is a continuation of this activity and an application of the acquired experience, in the realization of software systems suitable for use by people with disabilities. A team of specialists is working on a project funded by the National Science Fund (NSF) of Bulgaria, where research will be carried out in the field of mathematical methods for the analysis of physiological data. The project has the task of working on ensuring accessibility for people with visual deficits to a software system that performs physiological data analysis. In the process of designing and implementing the system, we will use the consultations of a participant from the team who has $100 \%$ visual impairment. The ultimate goal of one of the tasks of this project is to create a model or module that provides access to a computer system for processing and analysis of physiological data.

\section{Accessibility of software systems}

In order for a software system to be a available for a different group of people, it must be designed in such a way that it can be used by people with disabilities. It is necessary to ensure the use of appropriate specialized Input / Output devices that can facilitate access to the system. The following help devices for disabled users have been developed: screen reader, touchscreen, braille printer, customizable keyboards, and more.

The use of an information system by people with disabilities implies that they can work with it regardless of their physical problems: if the user has visual problem, he should be provided with a textual description of the graphics in the system; if the problem is auditory there should be created a textual description of the sound files included in the system; if he can not use a mouse there should be designed an opportunity to access all menus, windows and fields with the keyboard, graphical results should not be represented by a different colors (for example, a chart with different color rendering for different rezults for different parameters), but also in another way in which the color is one, because the daltonists can not distinguish the individual colors; for the people with vision impairment, the should be allow to increase the font size, etc.

The design of an information system based on the principle of universality should be preceded by a study of the ways in which people with disabilities can work with the system. They Should be provided with opportunities for the inclusion of new assistive technology devices and software products running on these devices. 
Web accessibility standards

In 1999, the WCAG Web Accessibility Standard (W3C Working Group) was released. In 2008, the second upgraded version - WCAG 2.0, was released. A new third editorial is expected to come out in 2018 to better address the needs of people with disabilities.

\section{Creating accessible software systems}

Each process of software creation passes through the following stages: preliminary study, design, programming of the individual modules, testing of the program modules created and system upgrading, and the use and maintenance of the created system. The stage of the preliminary study is very important, as it should highlight the basic requirements that consumers have with the system. Here is the stahe to determine the methods that will be used to realize the requirements of the users, to specify the expectations that the users have towards the system. Since, in general, people with disabilities do not know well the way software systems work, then the process of expectations followed by the realization options is most likely to be iterative. It is also a good idea for system designers and developers to consult with a larger number of people with different special needs, so they can more fully cover different aspects of the needs of people with disabilities and meet their expectations. It should be kept in mind that not everything will be clear at first. People with disabilities will not be able to explain enough what they want, how it would be convenient and possible for them to access the system. They live in our world without knowing well the opportunities that this world gives, and our world does not well respect the specific features of people with disabilities.

Stages of building the software system

The stages of creating the software system, which will be implemented as part of the tasks assigned to the NSF project team, are based on the traditionally applied stages of software product development (Nganji et al, 2011). In order to solve the tasks of the project, these stages will be carried out with the increased participation of the people with disabilities and in particular, people with a visual deficit.

Stages of realization of the software system (for analysis of physiological data):

1. The definition of system requirements. This is a preliminary study stage in which users with different special needs should be included.

2. The creating the system design.

3. Building a prototype system.

4. Testing the system. This stage must be carried out with the participation of the people with disabilities. It will take place under the guidance of a member of the team who has previous experience in solving tasks related to web accessibility for people with disabilities. This ensures that the requirements placed on the software system in relation to the specific needs of the people with disabilities will be considered and implemented in a way that is appropriate to that target group. A test with tasks can be created and to be performed by the participants in the study and feedback is thus obtained on the capabilities of the prototype for accessibility from the people with disabilities. Answering questions can help developers improve the features of the software system.

At this stage, the weak and good elements will be evaluated, and suggestions will be made to improve the modules. The stage is done by the team developing the system. There are suggestions for realization of the ideas from the previous stage to increase the accessibility of the system. The decision-making process will include a member of the Disability People's Team.

5. Improvement of the system. The step is performed by programmers. The design of software systems for people with disabilities has been investigated for systems with interfaces that are user sensitive (Gregor et al., 2002).

6. Creation of a second version of the programming system.

7. Implementation and exploitation of the system.

8. System maintenance. 
In order to solve the tasks that the team of specialists placed during the NSF project implementation, the authors will apply the following methods, some of which are similar to those found in past research (Gregor et al., 2002):

1. User-sensitive interface. Whether a particular user has no disability or has any form of visual deficit, he can effortlessly use the software system.

2. Providing custom interface capability. Providing the necessary means for the interface to be adapted to the specific needs of the people with disabilities. Creating the possibility to increase the font size, and to creat audio files that explain comprehensibly those parts of the software that can not be read by an electronic reader (suggested by Njanji et al, 2011).

3. Providing assistive technologies: screen readers, specialized keyboards, and so on. According to Landauer (1995), users with visual deficits may prefer listening to explanations made in an audio file rather than reading textual explanations.

4. Providing textual or audio explanations of the graphics used in the software program.

The experience of creating the software system can be used in the training of individuals with visual deficits as a form of extra, non-standard learning.

\section{Conclusion}

In this paper the authors describe the stages during which the design and implementation of a software system (for analysis of physiological data) will be implemented for the purposes of a project funded by NSF, Bulgaria. The software system will be implemented, providing the necessary functionalities, facilitating access to it by people with visual deficits. At the design stages of the system, it is intended to include people with a different form of visual deficit, who will be directed and led by a member of the team with $100 \%$ visual impairment and having relevant experience in solving web problems accessibility. The expected result is the creation of a software system for data analysis accessible to people with visual deficits. The development of this system will contribute to solving the accessibility problems of the software systems of the people with disabilities.

\section{Acknowledgements}

This work is partly funded by the National Science Fund of Bulgaria under the Research project № DM 12/36/20.12.2017, "Investigation of Mathematical Techniques of Analysis of Physiological Data with Functionality for People with a Visual Deficit".

\section{References}

Atanasova M., Malinova A. (2017) Transforming Concur Task Trees Model into an Abstract User Interface. CBU International Conference on Innovations in Science and Education. March 22-24, 2017, Prague, Czech Republic, 1036-1041. Retrieved from http://ojs.journals.cz/index.php/CBUIC/article/viewFile/1067/pdf

Balan R.V.S. and Punithavalli M. (2010) Software Architecture, Scenario and Patterns. International Journal of Computer Science Issues, Vol. 7, Issue 5, 418-423. Retrieved from http://paper.ijcsns.org/07_book/201010/20101009.pdf

Bogdanova G., N. Sabev, G. Tomov. (2016) Наръчник за уеб достъпност [Web Accessibility Guide], Horizons Fondation, Sofia“, Retrieved from http://webaccess.horizonti.bg/narychnik.

Bogdanova G., Sabev N., (2017) The second principle of operability in the standart for web accessibility WCAG 2.0., XVNational Conference with international participation "Libraries - reading-communications" - Digital conversion of literary and cultural heritage, 302-314.

Bogdanova G., Todorov T., Georgieva-Tsaneva G. (2017) Software Approaches and Methods to Ensure the Security of Interactive Systems. Cybernetics and Information Technologies. (in Press)

Ferre X., Juristo N., Windl H., Constantine L., (2001) Usability Basics for Software Developers. IEEE SOFTWARE, 22- 29. Retrieved from https://pdfs.semanticscholar.org/7324/6a8f539c42124276fba4c083a1078d6034d2.pdf

Georgieva-Tsaneva G. (2017) Същност на интерактивните системи, сигурност и достъпност. [Nature of Interactive System, Security and Accessibility]. Cultural and Historical Heritage: Preservation, presentation, digitalization. Volume 3, ISSN 2367-8038, 138-147, Retrieved from http://www.math.bas.bg/vt/kin/book-2017/10-KIN-2017.pdf

Georgieva-Tsaneva, G., Bogdanova, G., Sabev N. (2017) Characteristics of Interactivity and using the interactive Technologies in System North+. Seventh International Conference Digital Presentation and Preservation of Cultural and Scientific Heritage, Volume VII, IMI-BAS, Sofia, ISSN:1314-4006, 133-141.

Gregor P., Newell A.F. and Zajicek M. (2002) Designing for Dynamic Diversity - Interfaces for Older People. In Proceedings of The Fifth International ACM Conference on Assistive Technologies (ASSETS), Edinburgh, 151-156. Retrieved from https://www.researchgate.net/publication/221652287_Designing_for_dynamic_diversity_Interfaces_for_older_people 
ISO 9241-11:1998 , Ergonomic Requirements for Office Work with Visual Display Terminals, Geneva, 1998. Retrieved from https://www.scoop.it/t/arinefousin/p/4083960951/2017/08/30/iso-9241-11-usability-pdf-download

Landauer T. K. (1995) The Trouble with Computers: Usefulness, Usability and Productivity. MIT Press, Cambridge. Retrieved from https://quod.lib.umich.edu/cgi/t/text/text-idx?c=acls;cc=acls;view=toc;idno=heb01144.0001.001

Morgan M., McGee-Lennon M., Hine N., Arnott J., Martin C., Clark J., Wolters M. (2007) Requirements Gathering with diverse user groups and stakeholders, CHI 2007, San Jose, USA, 1-4. Retrieved from http://www.matchproject.org.uk/resources/documents/chi08-morgan.pdf

Nganji J. T. and Nggada S. H.(2011) Disability-Aware Software Engineering for Improved System Accessibility and Usability . International Journal of Software Engineering and Its Applications Vol. 5 No. 3, 47-62. Retrieved from http://www.sersc.org/journals/IJSEIA/vol5_no3_2011/5.pdf

Oviatt S. (2001) Designing Robust Multimodal Systems for Diverse Users and Environments:" In Workshop on Universal Accessibility of Ubiquitous Computing: Providing for the Elderly.

Petrie, H. (2009) The evaluation of accessibility, usability and user experience, The Universal Access Handbook, C Stepanidis (ed), CRC Press. Retrieved from http://www.nigelbevan.com/papers/The_evaluation_of_accessibility_usability_and_user_experience.pdf

Scottish Executive. (2004) First Report for the Range and Capacity Review of Community Care Services for Older People: Projections of Community Care Services Users, Workforce and Costs. Edinburgh, Scotland, UK. Retrieved from http://www.gov.scot/Publications/2004/07/19665/40326

Screen Reader User Survey \#7 Results, Retrieved from https://webaim.org/projects/screenreadersurvey7/

Sherman P. (2001) Cost-Justifying Accessibility. austin usability. Retrieved from https://www.ischool.utexas.edu/ 1385t21/AU_WP_Cost_Justifying_Accessibility.pdf

W3C (2000). Techniques for accessibility evaluation and repair tools. W3C Working Draft. Cambridge: W3C. Retrieved from https://www.w3.org/TR/AERT/

Ted S. Hasselbring, Candyce H., Glase W. (2000) Use of Computer Technology to Help Students with Special Needs, The Future of Children CHILDREN AND COMPUTER TECHNOLOGY, Vol. 10 • No. 2, 102-122. Retrieved from https://www.princeton.edu/futureofchildren/publications/docs/10_02_04.pdf

Tramonti M., Paneva-Marinova D., Pavlov R. Math and Art Convergence for Education. CBU International Conference on Innovations in Science and Education. March 22-24, 2017, Prague, Czech Republic, 851-854. Retrieved from http://ojs.journals.cz/index.php/CBUIC/article/view/1037

W3C (1999). Web content accessibility guidelines 1.0. W3C Recommendation. Cambridge: W3C. Retrieved from https://www.w3.org/TR/WAI-WEBCONTENT/

Web Content Accessibility Guidelines (WCAG) Overview, Retrieved from https://www.w3.org/WAI/intro/wcag

Web Content Accessibility Guidelines 1.0, Retrieved from http://www.w3.org/TR/WAI-WEBCONTENT/

Web Content Accessibility Guidelines (WCAG) 2.0, Retrieved from http://www.w3.org/TR/WCAG20/ 